\title{
Coupled Flow Modelling for a Geothermally Facilitated Bioreactor
}

\author{
Lucila B. Dunnington $^{1} \&$ Masami Nakagawa ${ }^{1}$ \\ ${ }^{1}$ Mining and Earth Systems Engineering, Colorado School of Mines, Golden, Colorado, USA \\ Correspondence: Lucila B. Dunnington, Mining and Earth Systems Engineering, Colorado School of Mines, \\ Golden, Colorado, 80401, USA. Tel: 1-757-289-4262. E-mail: ldunning@mymail.mines.edu
}

Received: February 27, 2018

Accepted: March 14, $2018 \quad$ Online Published: March 30, 2018

doi:10.5539/ep.v7n1p81

URL: https://doi.org/10.5539/ep.v7n1p81

\begin{abstract}
Abandoned mines across the world leak contaminated waters into precious water resources, threatening human populations and natural environments alike. The primary demand from the industry for addressing the contamination is a passive system that utilizes locally available and cheap material, with little energy or maintenance requirement. Passive treatment systems can operate in remote regions, using diverse, inexpensive, and locally available material with low waste production, but are subject to ambient conditions and are often space intensive. The geothermal gradient available at abandoned mines is a viable heat energy source that can provide advantageous temperature conditions for established remediation techniques, namely bioremediation.

Currently, the primary models used for testing new passive designs are either largely empirically based, or limit the scope of modelling parameters, making it difficult to incorporate innovative design aspects into the existing modelling framework. The following paper presents a model, based on kinetic parameters from a column experiment, which couples mechanics, thermodynamics, hydrodynamics, and microbial kinetics. The modelling results show the effect of an imposed temperature gradient on the permeability and microbially driven reactions of a bioreactor. The model reflects evolving thermal and mass transfer in the multiphase system. The addition of geothermal energy to a bioreactor is shown to improve long-term permeability, enhance reactions and precipitation kinetics, and decrease the necessary spatial expanse of designed bioreactor systems.
\end{abstract}

Keywords: direct-use, mining influenced water remediation, convection, coupled models

\section{Introduction}

In recent years bioreactors have been applied to various processes as a way to reduce the production of waste and decrease the necessary input of fossil fuel based energy into the processes (Campbell and Odgen, 1999). An extreme case of this is in the demand of passive systems for abandoned mine influenced water in remote regions (Johnson and Hallberg, 2002). Mine influenced water from abandoned mines can occur in remote areas devoid of man power or infrastructure. The bill of remediation often comes from taxpayer money, since the Clean Water Act only placed responsibility on the mining companies after 1972. The desire for an inexpensive, low-maintenance solution from the industry resulted in the development of various passive or semi-passive treatment systems: aerobic wetland, anaerobic wetland, lime drain, anoxic lime drain, permeable reactive barrier, etc. The limitations of current technologies include their tendency to stall in subfreezing environments, which is common in mountainous regions, and the space limitation of these same areas to allow for adequate residence time. Clogging also tends to occur in these systems a few months or years into their operation, due to compression of the lignocellulosic substrate.

Active systems avoid such problems with adequate temperature control, chemical or dissolved substrate addition, and mixing. These advantages have been thought to be unattainable in remote regions where passive treatment systems are desired. However the availability of a geothermal resource, often available from mine-associated hydrothermal systems, can potentially facilitate a remote passive bioreactor system. This paper compares the functions of a traditional passive mine water treatment system with one using a geothermal amendment, using computational flow modeling. A new model is also presented which fully couples thermodynamics with hydrodynamics and microbial kinetics, using Comsol Multiphysics ${ }^{\circledR}$ platform.

\subsection{Background}

Anaerobic digestion of compost and subsequent sulfate reduction is a multistep process. Essentially, raw compost is disintegrated; easily degraded organic components are consumed by bacteria, and then complex 
compounds namely lignin, cellulose and hemicellulose are broken down into simpler volatile fatty acids, carbon dioxide and hydrogen gas. The volatile fatty acids can be incorporated by sulfate reduction metabolic processes. Sulfate and organic acids are consumed and reduced sulfide and alkalinity are produced. The rate of these processes are dependent on the size of original organic particles, $\mathrm{pH}$, ammonium concentration, residence time in the system, and significantly temperature. Additionally, accumulation of organic acid if the sulfate reduction is too slow can have an inhibitory effect on the process. A recent study by Wang and Witarsa (2016) suggested that disintegration of raw compost was the rate limiting step, which departs from a common assumption that the fermentation of dissolved cellulosic and hemi-cellulosic material is the rate-limiting step of anaerobic lignocellulosic biomass digestion.

The rate of these processes more generally are dependent on the flow of their host medium. Accumulation of volatile fatty acids can occur in clogged or compressed systems, or dead zones in the designed system. The access of populations to nutrients can affect their rates and eventually the local bacterial composition. Additionally if the system is to be heated, preferential growth of bacterial in warmer areas may pose problems to the hydrodynamics and thermodynamics of the system. Thus these two factors- hydrodynamics and microbial kinetics- are interdependent. The Soret effect (mass transfer caused by the temperature gradient), and the Dufour effect (heat transfer caused by the concentration gradient) are often neglected in simulations of coupled buoyant forces (Zhao et al., 2008). Mansour et al. found that these interdependent effects greatly affect the mass and heat transfer in a free convection system (2008). Still various mass transfer and mechanical aspects have not been fully integrated into models of engineered bioreactor systems where a temperature gradient exists (Xie et al., 2016).

Computational flow modelling is rarely attempted for passive bioreactor systems, due to its complexity and computational cost. A computational flow model for this system could be invaluable for predicting utilization and compression of a substrate, longevity of the system, as well as designing unique area-specific treatment systems.

\section{Method}

Modeling of an anaerobic bioreactor system is tackled in various ways. Some people take a stoichiometric or purely bacterial approach, using one of several models developed for steady state flow through a dispersed biomass. The basic model is the Monod equation developed empirically to describe the onset of culture growth (Monod, 1949). Popular variations on this model include the Contois Model which includes long term kinetic parameters, and the Haldane Model which includes feedback mechanisms and different biochemical inhibitions. Another model, the pseudoanalytical biofilm model, specifically describes biofilm systems (Table 1). These models are based on the assumption that the flow in the system is completely mixed, uniform, and unchanging with bacterial growth. Fewer attempts have been made to couple hydrodynamic models to bacterial kinetic models for reasons including the computing complexity as well as the theoretical complexity that can be involved (eg. Gholamifard et al., 2008; Xie et al., 2016).

A passive bioreactor system has non-Darcian characteristics that are intimidating to address in a model, including a compressible matrix material, changing viscosity of fluid- particularly in non-isothermal flow, and an evolving multiphase flow. Additionally all forms of anaerobic digestion are non-isothermal, which requires another layer of complexity to the model, affecting viscosity, saturation "constants," growth and decay rates, precipitation, dissolution, diffusion, density, etc. Often if temperature is added to a model it is only added in a limited fashion, for instance only reaction rate. Consequently many operators rely on empirical models to handle temperature variation around an anaerobic bioreactor (Table 2). 
Table 1. Commonly employed microbial growth and substrate consumption models

\begin{tabular}{|c|c|c|}
\hline Name & & Uses \\
\hline $\begin{array}{l}\text { Monod Kinetic } \\
\text { Model }\end{array}$ & $r_{u t}=-q \frac{S}{K+S} X_{a}$ & $\begin{array}{l}\text { Incipient bacterial } \\
\text { growth }\end{array}$ \\
\hline $\begin{array}{ll}\text { Contois } & \text { Kinetic } \\
\text { Model } & \\
\end{array}$ & $r_{u t}=-\frac{\mu_{m}}{Y} \frac{S B}{K_{x} B+S}$ & $\begin{array}{l}\text { Long term bacterial } \\
\text { growth }\end{array}$ \\
\hline $\begin{array}{l}\text { Haldane Kinetic } \\
\text { Model }\end{array}$ & $q_{e f f}=\frac{q}{1+\frac{S}{K_{I S}}} \quad K_{e f f}=\frac{K}{1+\frac{S}{K_{I S}}}$ & $\begin{array}{lr}\text { Adjustments to } \\
\text { Monod kinetics for } \\
\text { competitive and } \\
\text { uncompetitive } \\
\text { inhibition }\end{array}$ \\
\hline $\begin{array}{l}\text { Psuedoanalytical } \\
\text { Biofilm model }\end{array}$ & $\frac{\left(\tanh \left[\alpha\left(\frac{S_{s}^{*}}{S_{\min }^{*}}-1\right)^{\beta}\right]\right)\left(2\left[S_{s}^{*}-\ln \left(1+S_{s}^{*}\right)\right]\right)^{\frac{1}{2}}}{K^{*}}$ & $\begin{array}{lr}\text { Descriptive } & \text { of } \\
\text { biofilm systems, } \\
\text { with insoluble } \\
\text { substrate. } \\
\text { solveratively }\end{array}$ \\
\hline
\end{tabular}

Table 2. Empirically derived equations showing impact of temperature on bioreactor performance

\begin{tabular}{lll}
\hline $\begin{array}{l}\text { Efficiency } \\
\text { (Chernicharo, 2007) }\end{array}$ & $E_{T}=1-\left(1-E_{30}\right) \theta^{T-30}$ & $\begin{array}{l}\mathrm{T} \text { is operational temperature and } \\
\text { theta is the temperature coefficient, } \\
\text { between } 1.02 \text { to } 1.04\end{array}$ \\
\hline $\begin{array}{l}\text { Growth rate } \\
\text { (Henze and Harremoes, 1983) }\end{array}$ & $k(t)=k_{30} \times 1.11^{T-30}$ & $\begin{array}{l}\mathrm{k}(\mathrm{t}) \text { is growth rate of anaerobic } \\
\text { bacteria, } \mathrm{T} \text { is temperature in } \mathrm{C}\end{array}$ \\
\hline $\begin{array}{l}\text { Kinematic viscosity of fluid } \\
\text { (Hotlos and Jaskula, 1988) }\end{array}$ & $v(x, y, T)=10^{-11} \times(164+48 x$ & $\begin{array}{l}\text { Where } \mathrm{x} \text { is the concentration of } \\
\text { metal sulfate in the solution, y is } \\
\text { the amount of sulfuric acid in the } \\
\text { system, and } \mathrm{T} \text { is the absolute } \\
\text { temperature. }\end{array}$ \\
& $+13 y+32 x^{2}$ \\
& $\times 2 x y+3 y^{2}$ \\
&
\end{tabular}

While empirical models are useful for controlled operations, they lack a theoretical basis, and thus cannot be predictive for evolving or unique systems (Hamelers, 2004).

Various studies on the theoretical aspects of bioreactor systems have been conducted, but the integration of these theories into the industry standard is slow. By using a commercially available software, such as Comsol Multiphysics, the gap between the theoretical and practical for applications of bioreactors can close.

\subsection{Heat Stimulation of Mixing and Hydrodynamics}

The addition of heat in a low Reynolds number system not only adds heat to increase reaction rates, it also stimulates free convection in the tank. Leachate recirculation has been shown to enhance biodegradation in anaerobic landfill settings. Liquid movement distributes cultivated bacteria sloughed off from biofilms, circulates nutrients and dilutes toxic materials introduced in new material (Gholamifard et al., 2008; Novella et al., 1997). An additional feature of heat stimulated mixing is the production of convection cells. Free convection in the system can change unidirectional flow into a multidirectional flow, which distributes the pressure in the system, potentially alleviating clogging that persists in many passive treatment apparatuses. In the case of heated systems, mixing can also distribute heat so that reactions happen evenly. The water moving through an open wetland system should have a low average velocity to promote settling and sufficient hydraulic residence time for treatment of the contaminant. Slow moving water can accommodate mixed convection, whereas some faster systems would overwhelm the buoyant convection.

Problems with passive systems have included insufficient space in the winter for treating to the target contaminant level, and clogging or flow-through, resulting in short circuiting the designed residence time, in the 
system over time. It is apparent why the first issue could be addressed with a geothermal addition- adding heat increases performance of the microbes in the bioreactor, and even increases solubility of the cellulosic material (Veeken and Hamelers, 1999). The second problem could also be aided with a heating element. As convection induces multidirectional movement in a reactor as opposed to the predominantly unidirectional movement in a reactor, the compression of the lignocellulosic biomass may be reduced.

Comsol is used to couple the hydrodynamics, thermodynamics, and microbial kinetics of this process in this modeling effort. The effect of water in a geothermally convecting system on microbial kinetics is evaluated to potentially benefit remote abandoned mine passive systems. Temperature's effect on fluid volume force is added to the model as well as in substrate uptake and microbial growth and decay models. Two heated surfaces are placed on the base of a two-dimensional model to represent flowing geothermal waters. The temperature of these plates are set at $313 \mathrm{~K}$ to match geothermal waters from a test site in Rico, Colorado, and also use a temperature attainable at many abandoned hydrothermal ore deposit mines in the western United States (Lawson and Sonderegger, 1978). Walls of the tank are made to be $278 \mathrm{~K}$ as is typically of $5-10 \mathrm{ft}$ ground temperatures in winter of mountainous areas in Colorado. Influent water enters from the upper left side of the tank and the water is at $289 \mathrm{~K}$ as is typical for mine water effluent and the case in the mine of Rico.

Once the water has entered the box, it is subjected to the temperature gradient of the geothermal addition and outside condition. The density of the water changes with temperature, resulting in buoyant convection. Buoyant convection creates mixing cells in the system, which are considered useful for the distribution of nutrients and temperature, as well as diluting the incoming contaminated stream.

The effects of $\mathrm{pH}$ and viscosity are not considered in the model, even though at $5^{\circ} \mathrm{C}$ pure water has a steeply changing viscosity. Viscosity also changes with biomass dissolution and iron sulfate precipitation. Density is addressed in a limited way, as the model expresses a degree of thermal expansion of water as the water's temperature changes, leading to the convection observed in the model.

For the hydrodynamics of this system, Stokes flow was used, with incompressible flow, and neglecting the inertial term.

$$
\begin{gathered}
\frac{\partial u}{\partial t}+u \frac{\partial u}{\partial x}+v \frac{\partial u}{d y}+\frac{\partial P}{\partial x}-v\left(\frac{\partial^{2} u}{\partial x^{2}}+\frac{\partial^{2} u}{\partial y^{2}}\right)=0 \\
\frac{\partial v}{\partial t}+u \frac{\partial v}{\partial x}+v \frac{\partial v}{d y}+\frac{\partial P}{\partial y}-e g k(T)-v\left(\frac{\partial^{2} v}{\partial x^{2}}+\frac{\partial^{2} v}{\partial y^{2}}\right)=0 \\
\frac{\partial T}{\partial t}+u \frac{\partial T}{\partial x}+v \frac{\partial T}{\partial y}-k(T)\left(\frac{\partial^{2} T}{\partial x^{2}}+\frac{\partial^{2} T}{\partial z^{2}}\right)=0 \\
\frac{\partial u}{\partial x}+\frac{\partial v}{d y}=0
\end{gathered}
$$

The first two equations are the Navier Stokes equations with temperature modification, the third equation is for heat conduction and the fourth equation is the continuity equation. The creeping flow module was used in Comsol, with flow constricted to flowing within a matrix of $80 \%$ porosity, corresponding with porosity in a lignocellulosic substrate matrix.

\subsection{Thermodynamics}

Heat transfer in this model takes place in the liquid phase and solid phase or the porous system. The governing equations are

$$
\begin{gathered}
d\left(\rho C_{p}\right)_{e f f} \frac{\partial T}{\partial t}+d \rho C_{p} \boldsymbol{u} \nabla T+\nabla \boldsymbol{q}=d Q+q_{0}+d Q_{v d}+d Q_{g e o} \\
\boldsymbol{q}=-d k_{e f f} \nabla T \\
\left(\rho C_{p}\right)_{e f f}=\sum_{i} \theta_{p i} \rho_{p i} C_{p, p i}+\left(1+\sum_{i} \theta_{p i}\right) \rho C_{p} \\
k_{e f f}=\sum_{i} \theta_{p i} k_{p i}+\left(1+\sum_{i} \theta_{p i}\right) k+k_{g}+k_{d i s p}
\end{gathered}
$$


The values used for water the heat capacity and conduction of matrix material were gathered from studies on porous low-decomposition peat material. Effective parameters of heat capacity, density, and temperature are taken from the porous domain.

\subsection{Mass Transfer}

The mass transfer of chemically reacting species includes convection, adsorption, and dispersion in porous media, but the temperature dependence of adsorption and dispersion were not included in this model. The temperature effects were included in the microbially facilitated chemical reactions.

$$
\begin{gathered}
\frac{\partial c}{\partial t}+\nabla(-D \nabla c)+\boldsymbol{u} \nabla c=R \\
\boldsymbol{N}=-D \nabla c+\boldsymbol{u} c
\end{gathered}
$$

A first order temperature dependent model was used to model the kinetics as fluid moved through the system. Experimentally derived substrate consumption rate for $22^{\circ} \mathrm{C}$ was used as the reference, and a temperature dependent half-saturation constant was applied in the Monod Equation. The bacterial population was held constant for this study under the assumption that the biofilm population was constrained by surface area of lignocellulosic biomass in a bioreactor (Kovach et al., 2015).

An Arrhenius function, with temperature dependent first order rate was applied to the kinetics of dissolving cellulosic material, which corresponds to the removal of contaminant removal from the influent. The activation energy and universal gas constant were constant.

$$
k=A_{f} e^{\frac{-E}{R T}}
$$

The activation energy E was taken to be $43 \mathrm{~kJ} / \mathrm{mol}$ and $\mathrm{A}_{\mathrm{f}}$ as $34.9 \mathrm{~s}^{-1}$ based on experimental parameters.

\section{Results}

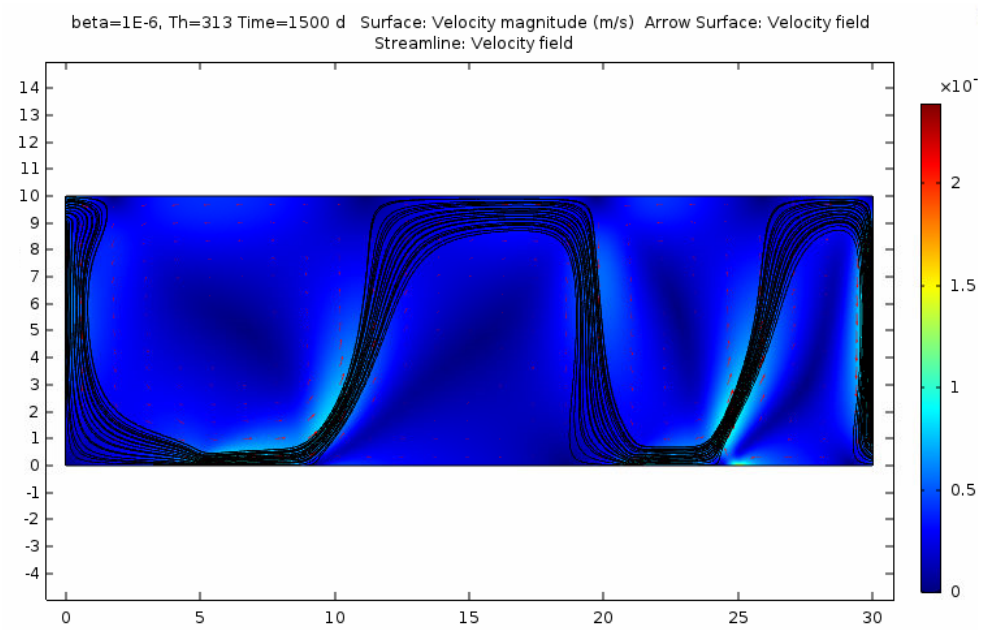

Figure 1. Velocity surface plot of the heated reactor design, warmer colors represent faster flow, the black lines show flow streamlines and the red arrows show flow direction

The results of the study were reviewed after the model simulated 1500 days of system function. The model shows the result of mixed convection in the system: thermally driven free convection from the bottom heat plates as well as inflow from the top left and outflow from the bottom right at a velocity of $5 \mathrm{e}-6 \mathrm{~m} / \mathrm{s}$. 


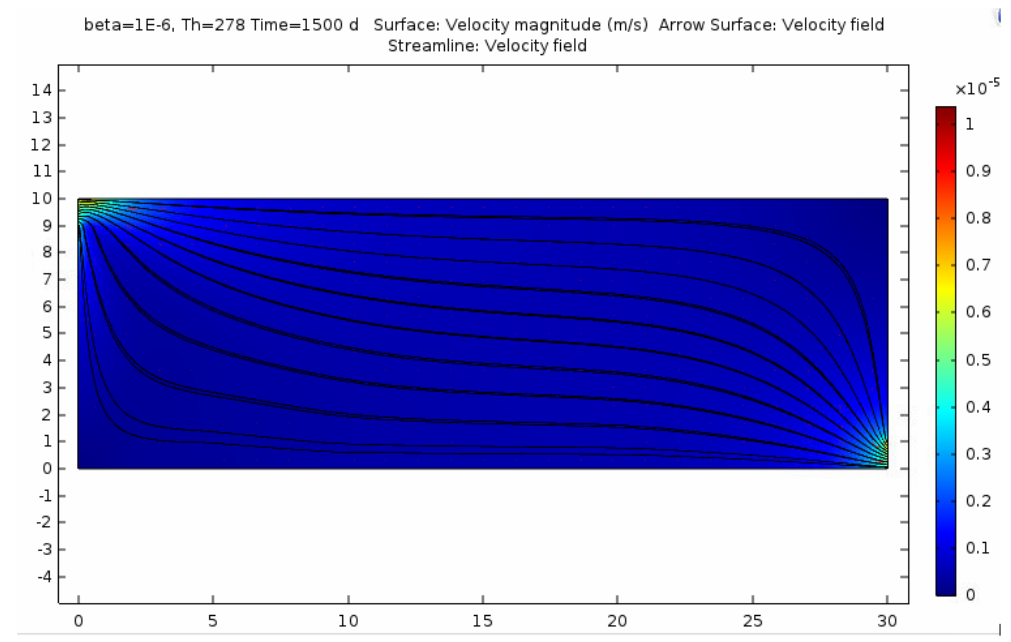

Figure 2. Velocity surface plot of non-heated reactor design, streamlines spread through system

Immediately it is apparent that the thermally driven flow provides more regular flow path for the water (Figures 2 and 3). The black lines are streams lines from the inlet to the outlet of the tank, the red arrows are velocity vectors that show the direction of water travel. Rather than taking many flow paths with disparate residence times, the water in the heat treated system is subjected to a single, tortuous flow path through the tank. The centers of the convection cells may be shown to accumulate larger particles if investigated further.

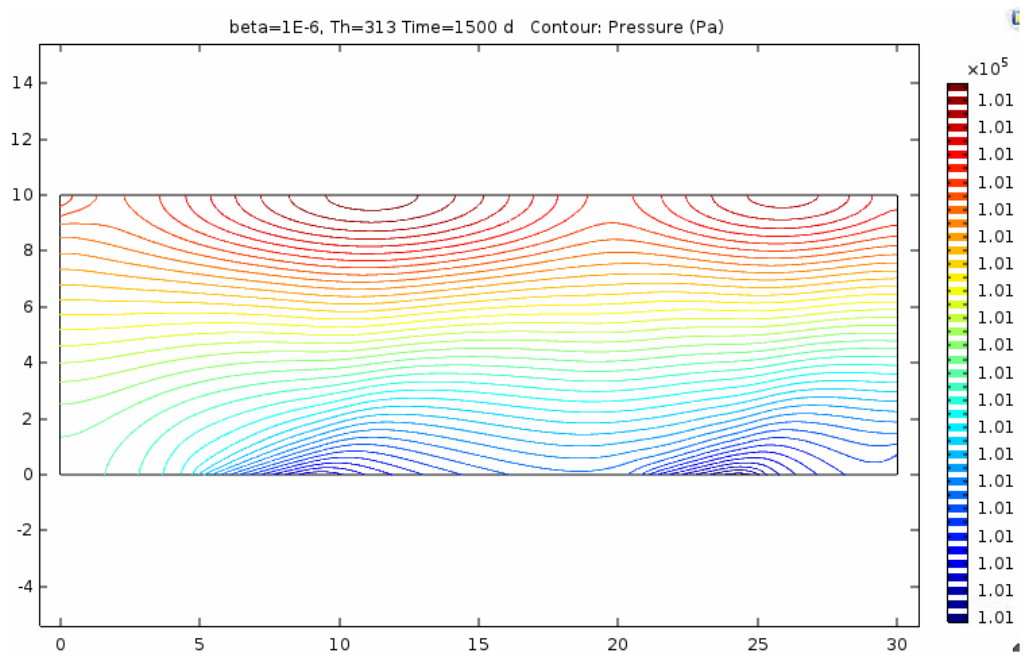

Figure 3. Pressure contours of heated system; Warmer colors represent higher pressure; Prominent pressure gradient oriented parallel to inlet and outlet 


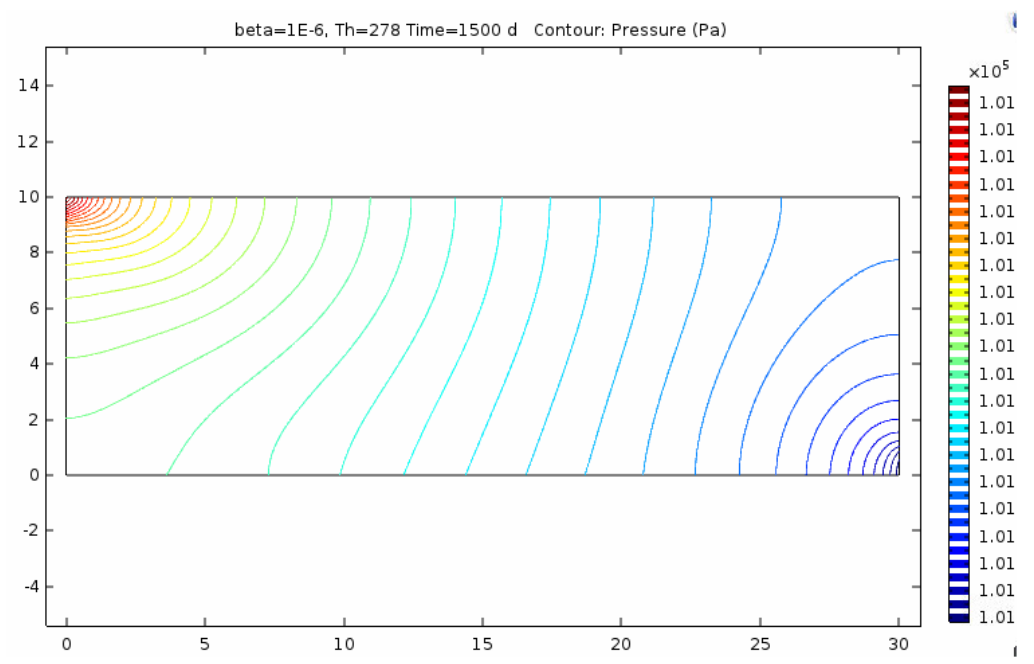

Figure 4. Pressure contours of non-heated system simulation. Prominent pressure gradient oriented perpendicular to inlet and outlet

In the pressure contour figures, the prominent temperature gradient is visible. With the heated system, the prominent pressure gradient is vertically oriented, rather that horizontally oriented as in the non-heated system (Figures 3 and 4). The orientation of the pressure gradient indicates where compression of the substrate may occur. Rather than accumulate at the outflow, producing clogging, the heated system will compress material perpendicular to the predominant flow of the system. This facet may increase the longevity of passive treatment systems in the field.

Whereas in a traditional system the natural available heat from mine groundwater is quickly dissipated to the cold outside environment, a heated system can use the local heat sources to passively dissipate heat in the tank reactor (Figure 5).

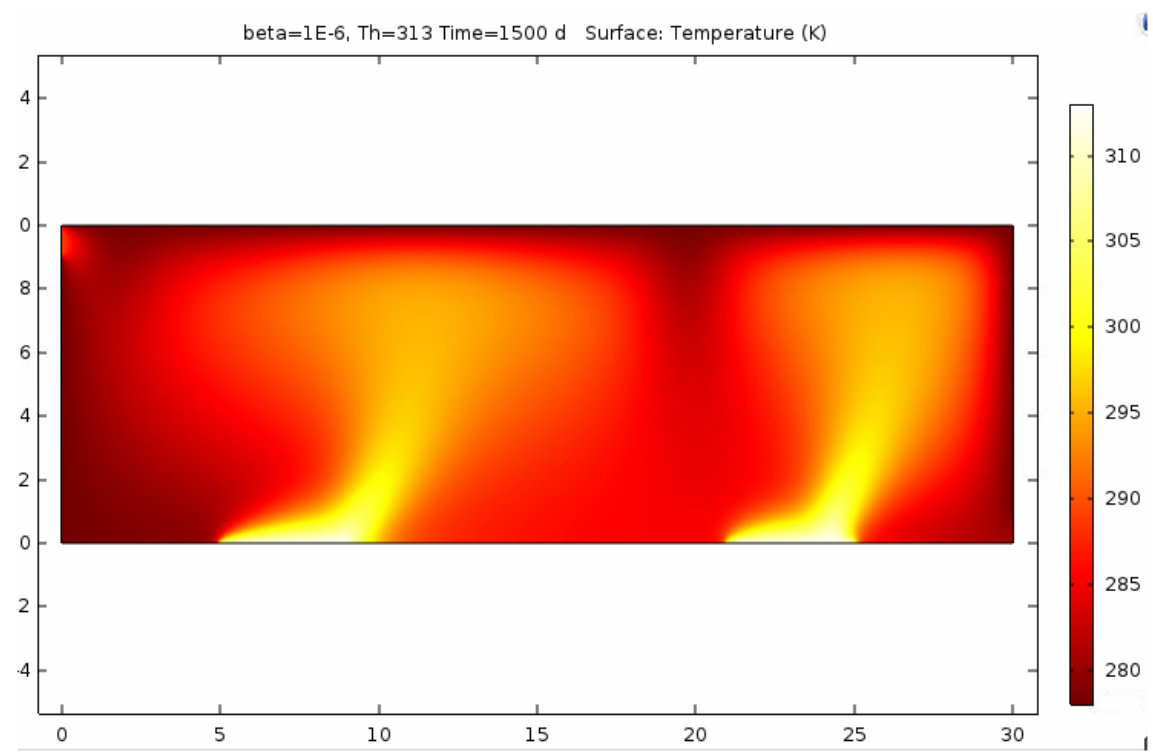

Figure 5. Temperature plot of heated system showing heat distribution in the mixed convection system (Non-heated system not shown) 


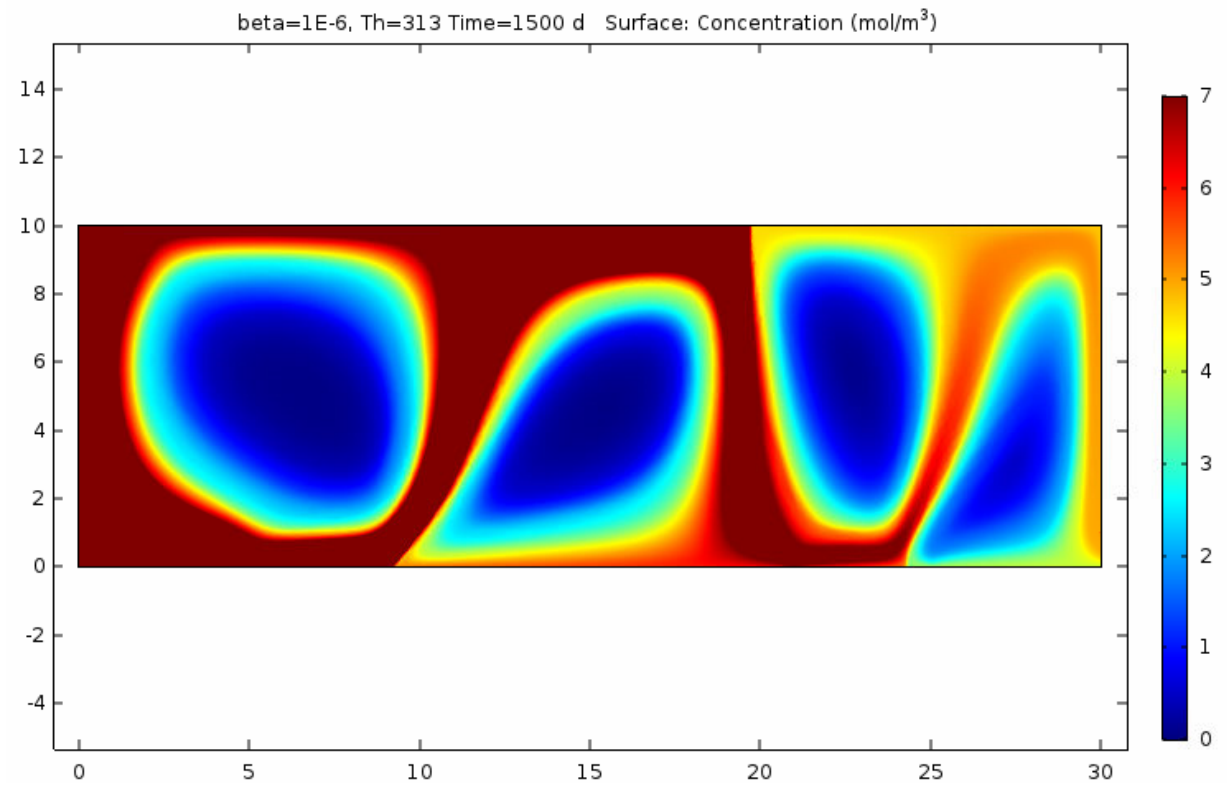

Figure 6. Concentration surface of heated system at day 1500 of simulation

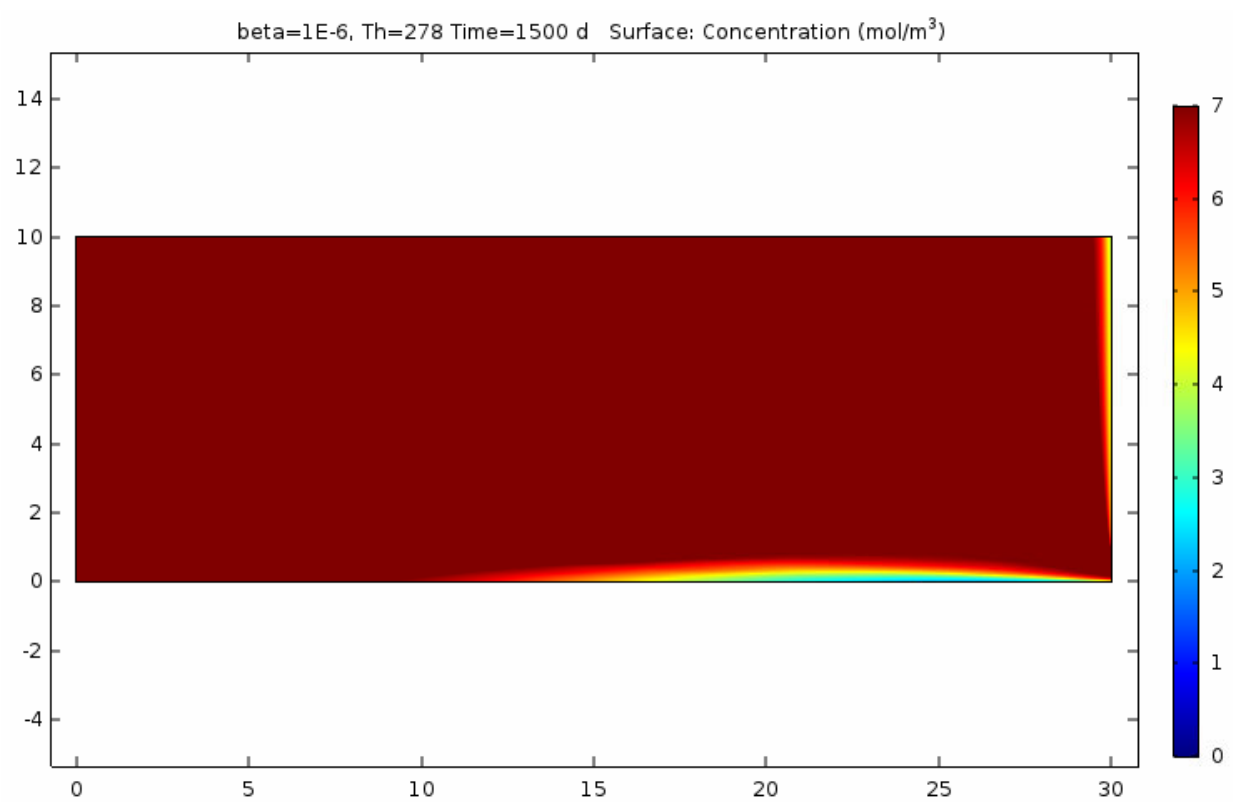

Figure 7. Concentration surface plot of non-heated system at day 1500 of simulation

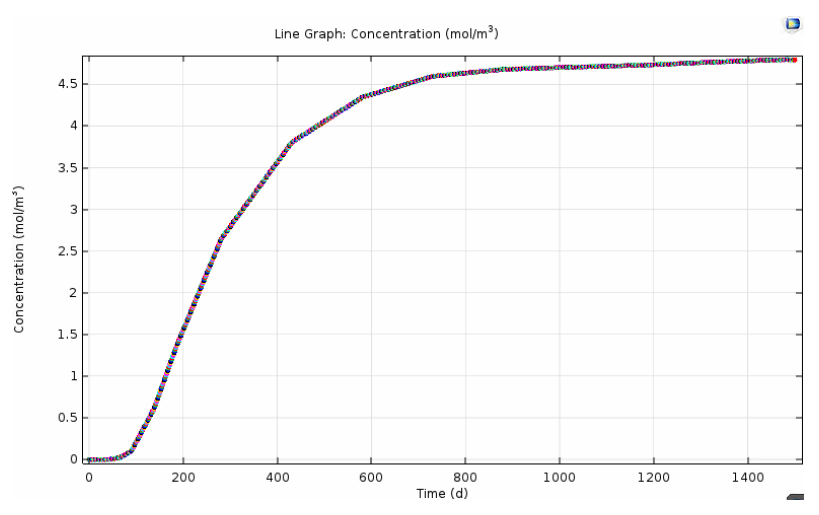




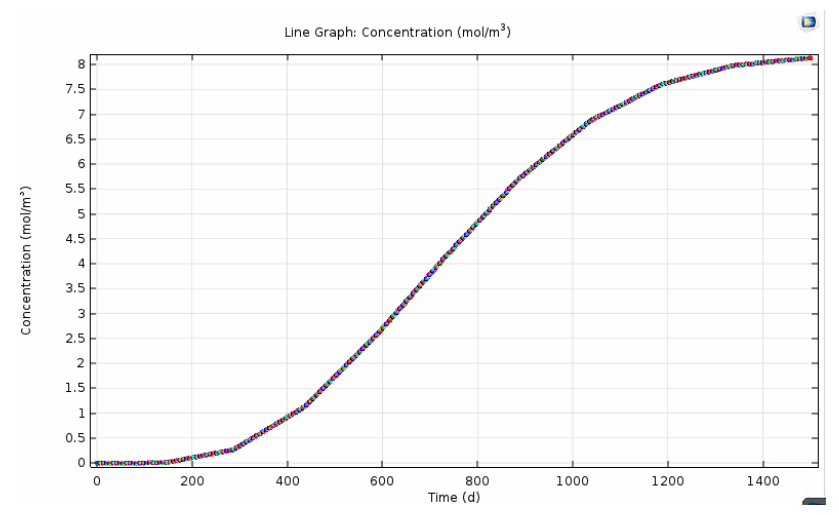

Figure 8. Graphs on the average outlet concentration of the simulated contaminant. The left is the heated system and the right is the non-heated system

The surface concentration plots show the distribution of contaminant in the tank reactor (Figure 6 and 7). By the simulated $1500^{\text {th }}$ day, contaminant is fully dispersed in the cool tank and the average concentration at the outlet is shown in Figure 8. The first graph shows the result of the outlet with a heating element and the second graph shows the outlet without a heating element. From an initial inflow of $15 \mathrm{~mol} / \mathrm{m}^{3}$, the heated tank reduced the concentration of the contaminant to about $5 \mathrm{~mol} / \mathrm{m}^{3}$ while the cold tank reduced it to about $8.5 \mathrm{~mol} / \mathrm{m}^{3}$. The $40 \%$ decrease in contaminant outlet can also be translated to a $40 \%$ decrease in the space required for treatment, from a construction or financial standpoint. While diffusion to the center of convection cells essentially limits space utilized by the system, the overall benefit from reduced dispersion and added heat significantly improves the efficiency of the system- not only improving treatment per area, but also improving the pressure gradient which affects eventual compression and clogging.

\subsection{Seasonal Stability}

In order to study the seasonal stability of the cells, the simulation was run to approximate a summer temperature outside of the convection tank, or $15^{\circ} \mathrm{C}$, the recorded ground temperature of high altitude sites tested in Colorado.

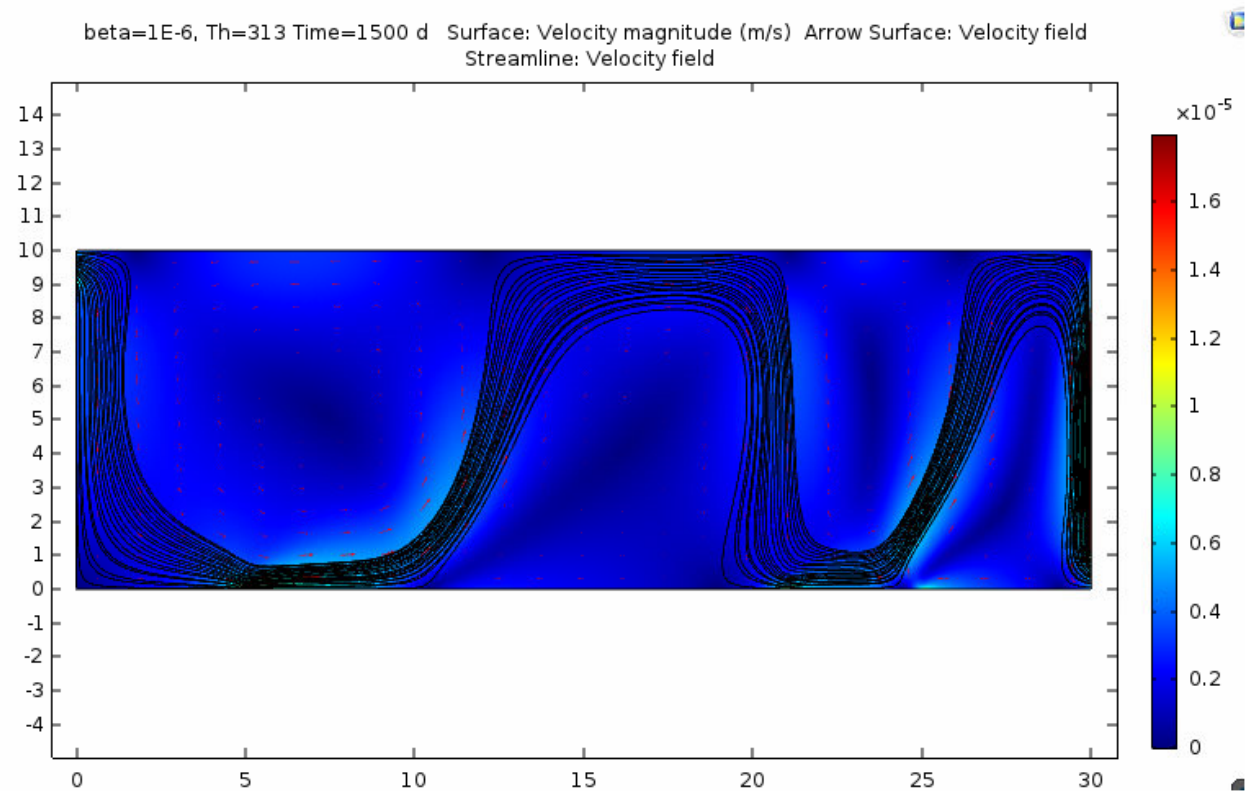

Figure 9. Outside temperature is changed from $5^{\circ} \mathrm{C}(278 \mathrm{~K})$ to $15^{\circ} \mathrm{C}(288 \mathrm{~K})$ to investigate the effect of seasonal temperature variability impacts flow in heated system; Free convection cells in mixed convection system still partially intact 
The convection cells remain intact in this temperature gradient as well, even though the streamlines are less tightly held. The widening band of streamlines indicates more dispersion in the upper half of the tank, and the warm tank outflow average concentration is further reduced to $2.2 \mathrm{~mol} / \mathrm{m}^{3}$ (Figure 10).
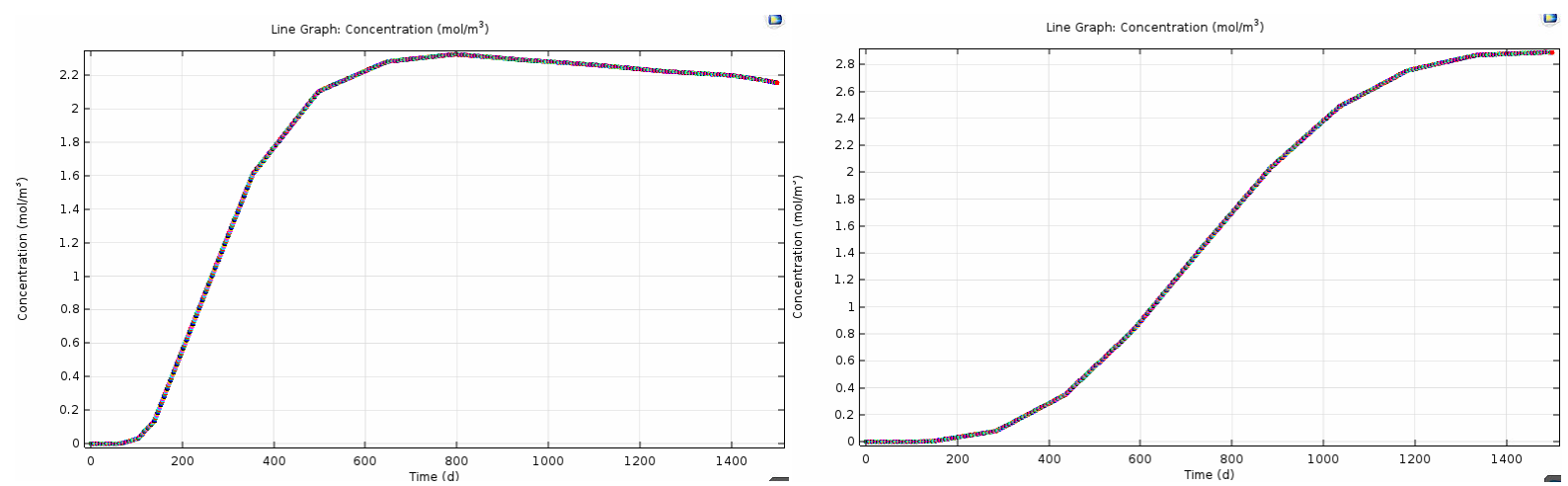

Figure 10. Graphs on the average outlet concentration of the simulated contaminant for the summer condition. The left is the heated system and the right is the non-heated system

The difference between the summer heated and cool tanks is predictably less considerable with only about a 0.8 $\mathrm{mol} / \mathrm{m}^{3}$ difference in average outlet concentration (Figure 10).

While the heated bioreactor provides a passive energy source to increase reaction rates within a bioreactor system, the convection cells formed effectively removed some volume from the system. The overall effect of reduced dispersion and added heat, compared to the non-geothermal system, is beneficial to bioreactor's efficiency.

\subsection{Successive Bacterial Growth}

The bacterial plot does not show growth correlate with permeability in the system (Figure 11), as such progressive changes in the permeability and flow path of the reactor are not captured in the current simulation. The simulation only shows the tendency of bacteria to accumulate in certain regions of the designed reactor.

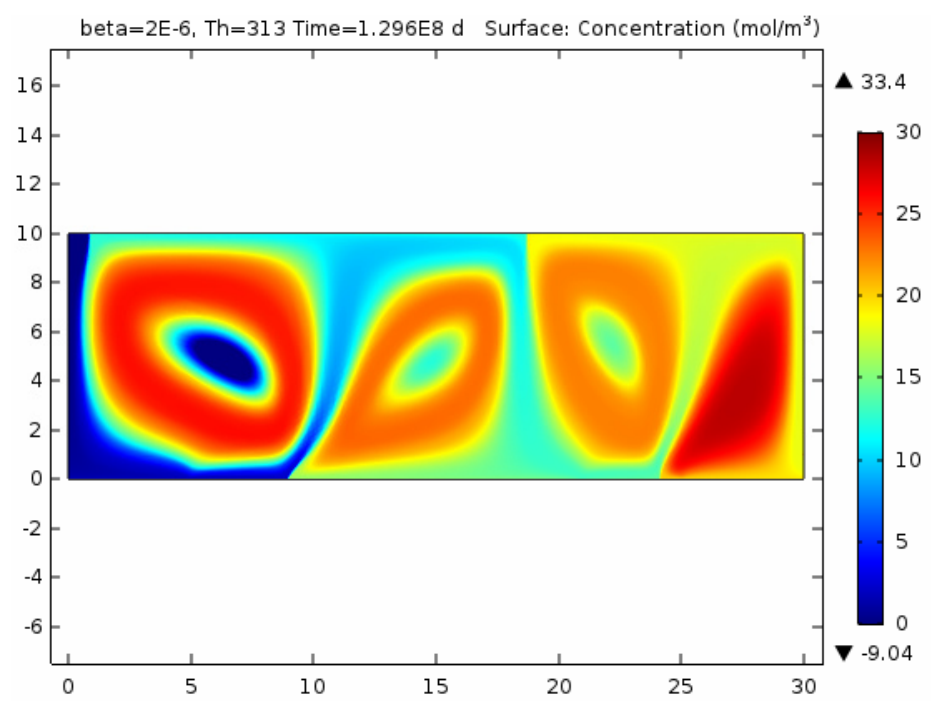

Figure 11. Sulfate reducing bacteria growth in tank reactor at day 1500. Warmer colors representing higher concentrations

Higher concentrations of bacteria tend to form on the periphery of dominant flow in the first half of the reactor, and then in the dominant flow path in the second half of the reactor. NMR data analyzed in an associated study has shown that the growth of anaerobic biofilms decreases the local effective porosity in a system significantly, up to $50 \%$. The local growth in bacteria corresponds with increased flow velocity in the same space. The colocation of higher velocities and increased bacterial growth could have implications for the tank design. A decrease in permeability at a rapid flow channel could stress the laminar flow conditions of the system, 
increasing local turbulence and dispersion.

\section{Discussion}

The removal rate of the regular tank in the winter condition removed $43.3 \%$ of the influent contaminant, while the heated tank effectively removed $66.7 \%$ of the influent contaminant. In the summer condition, the heated tank could remove $85.3 \%$ of the influent contaminant and the cool tank removed about $80 \%$. The use of computational flow modeling in this case study allowed an insight into the added potential mechanical benefits of a heated system as well. Where the traditional systems allow for dispersion and unidirectional flow, the heated system provides a stricter streamline for flow to follow through the tank, with mixed convective flow. The convection observed in this model however reduces the effective reactor volume by constricting flow to the convection cells. Overall the benefit of the heat and dispersion reduction outweighed the reduction in effective volume, making the heated system more space efficient.

By integrating computational flow modeling into bioreactor system design, the types of reactors possible will not be limited to basic settling designs. Environmental treatments that fit the landscape or utilize locally available materials and energy sources may be possible to create more efficient systems in remote areas. Additionally, a visualization of the coupled system allows engineers to inspect where clogging due to bacterial growth or substrate decay could occur, and design systems to withstand the hydrodynamic effects of compression of decaying organic material.

\section{Acknowledgements}

The authors would like to thank the Town of Rico, Colorado for their acceptance of our research group into their land and community, allowing us to conduct tests around hot spring bathers, and for their participation in informational meetings regarding findings. Thanks also go to the Colorado School of Mines for facilities and technology for the simulations, NMR tests and laboratory confirmations of this research, not yet published.

\section{References}

Campbell, C. S., \& Ogden, M. H. (1999). Constructed wetlands in the sustainable landscape (Vol. 3). John Wiley \& Sons.

Canfield, D. E., Olesen, C. A., \& Cox, R. P. (2006). Temperature and its control of isotope fractionation by a sulfate reducing bacterium. Geochimica et Cosmochimica Acta, 70, 548-561. Retrieved from https://www.sciencedirect.com/science/article/pii/S0016703705008100

Gholamifard, S., Eymard, R., \& Duquennoi, C. (2008). Modeling aerobic bioreactor landfills in methanogenic phase: Long term and short term behaviors. Water Research, 42(20), 5061-5071. Retrieved from https://www.sciencedirect.com/science/article/pii/S004313540800420X

Hamelers, H. V. M. (2004). Modeling composting kinetics: A review of approaches. Reviews in Environmental Science \& Bio/Technology, 3, 331-342. Retrieved from https://ink.springer.com/article/10.1007/s11157-004-2335-0

Hotlos, J., \& Jaskula, M. (1988). Densities and viscosities of $\mathrm{CuSO}_{4}-\mathrm{H}_{2} \mathrm{SO}_{4}-\mathrm{H}_{2} \mathrm{O}$ Solutions. Hydrometallurgy, 21, 1-7. Retrieved from https://www.sciencedirect.com/science/article/pii/0304386X88900126

Johnson, D. B., \& Hallberg, K. B. (2002). Pitfalls of passive mine water treatment. Re/Views in Environmental $\begin{array}{lllll}\text { Science \& Bio/Technology, } 1, \quad 335-343 . & \text { Retrieved from }\end{array}$ https://link.springer.com/article/10.1023/A:1023219300286

Kovach, K., Davis-Fields, M., Rodesney, C., \& Gordon, V. (2015). Measuring the mechanics of biofilms at multiple lengthscales. SPIE, University of Texas, Austin. $\mathrm{http} / / /$ spie.org/newsroom/5754-measuring-the-mechanics-of-biofilms-at-multiple-lengthscales?SSO=1

Lawson, D. C., \& Sonderegger, J. L. (1978). Geothermal database study: mine-water temperatures. Final Report. Montana Bureau of Mines and Geology, Butte, USA, Montana Coll. of Mineral Science and Technology.

Mansour, M. A., El-Anssary, N. F., \& Aly, A. M. (2008). Effects of chemical reaction and thermal stratification on MHD free convection heat and mass transfer over a vertical stretching surface embedded in a porous media considering Soret and Dufour numbers. Chemical Engineering Journal, 145, 340-345. Retrieved from https://www.sciencedirect.com/science/article/pii/S1385894708005238

Monod, J. (1949). Growth of Bacterial Cultures. Annu Rev Microbiol, 3, 371-394. Retrieved from https://www.annualreviews.org/doi/abs/10.1146/annurev.mi.03.100149.002103

Novella, P. H., Ekama, G. A., \& Blight, G. E. (1997). Effects of liquid replacement strategies on waste 
stabilization at pilot-scale. Proceeding of 6th Landfill Symposium 1, Calgari, Italy, 387-396.

Pavlostathis, S. G, \& Giraldo-Gomez, E. (1991). Kinetics of Anaerobic Treatment. Water science and Technology, 24, 35-59. Retrieved from https://www.tandfonline.com/doi/abs/10.1080/10643389109388424

Veeken, A., \& Hamelers, B. (1999). Effect of temperature on hydrolysis rates of selected biowaste components. Bioresources, 69(3), 249-254. $\quad$ Retrieved from https://www.sciencedirect.com/science/article/pii/S0960852498001886

Wang, Y., \& Witarsa, F. (2016). Application of Contois, Tessier, and first order kinetics for modeling and simulation of a composting decomposition process. Bioresource Technology, 220, 384-393. Retrieved from https://www.sciencedirect.com/science/article/pii/S0960852416312378

Xie, S., Hai, F. I., Zhan, X., Guo, W., Ngo, H. H., Price, W. E., \& Nghiem, L. D. (2016). Anaerobic co-digestion: A critical review of mathematical modelling for performance optimization. Bioresource Technology, 222, 498-512. Retrieved from https://www.sciencedirect.com/science/article/pii/S0960852416314213

Zhao, F., Liu, D., \& Tang, G. (2008). Natural convection in an enclosure with localized heating and salting from below. International Journal of Heat and Mass Transfer, 51, 2889-2904. Retrieved from https://www.sciencedirect.com/science/article/pii/S0017931007006072

\section{Copyrights}

Copyright for this article is retained by the author(s), with first publication rights granted to the journal.

This is an open-access article distributed under the terms and conditions of the Creative Commons Attribution license (http://creativecommons.org/licenses/by/4.0/). 